\title{
Hot environment aggravated hemorrhagic shock- induced organ dysfunction and protective effects of cold fluid resuscitation
}

\section{Yu Zhu}

Third Military Medical University Daping Hospital and Research Institute of Surgery

\section{Sheng Ma}

Third Military Medical University Daping Hospital and Research Institute of Surgery

\section{Haoyue Deng}

Third Military Medical University Daping Hospital and Research Institute of Surgery

\section{Han She}

Third Military Medical University Daping Hospital and Research Institute of Surgery

\section{Jie Zhang}

Third Military Medical University Daping Hospital and Research Institute of Surgery

\section{Kunlun Tian}

Third Military Medical University Daping Hospital and Research Institute of Surgery

\section{Liangming Liu}

Third Military Medical University Daping Hospital and Research Institute of Surgery

\section{Tao Li ( $D$ lt200132@163.com )}

Third Military Medical University Daping Hospital and Research Institute of Surgery https://orcid.org/0000-0002-9643-5185

\section{Research}

Keywords: hot environment, hemorrhagic shock, organ function, hypothermic resuscitation

Posted Date: May 7th, 2021

DOI: https://doi.org/10.21203/rs.3.rs-496472/v1

License: (c) (1) This work is licensed under a Creative Commons Attribution 4.0 International License. Read Full License 


\section{Abstract \\ Background}

There are more and more areas with hot environment. Whether hot environment can aggravate hemorrhagic shock-induced organ dysfunction and its pathophysiological mechanism and treatment remains unclear.

\section{Methods}

Hemorrhagic shock rat model in hot environment was used to observe the changes of vital organ functions, the variation of the internal environment, stress factors and inflammatory factors, meanwhile, the targeted prevention and treatment measures were further studied.

\section{Results}

Hot environment further aggravated hemorrhagic shock induced death even in $34^{\circ} \mathrm{C}$ hot environment which core temperature was not increased. At the same time, functions of heart, liver and kidney were more damaged after hemorrhagic shock rats in $34^{\circ} \mathrm{C}$ hot environment as compared with room environment. The further study showed that the blood concentration of $\mathrm{Na}^{+}, \mathrm{K}^{+}$and plasma osmotic pressure, the expression of inflammatory factors tumor necrosis factor-a (TNF-a) and interleukin-6 (IL-6) in the serum, as well as the stress factors Adrenocorticotropic Hormone (ACTH) and Glucocorticoid (GCS) were all notably enhanced following hot environment with hemorrhagic shock; and acidosis was extraordinary obvious; oxygen supply and oxygen consumption were remarkably decreased. At last present study demonstrated that $4-10^{\circ} \mathrm{C}$ hypothermia fluid resuscitation could significantly improve the survival rate in hemorrhagic shock rats with hot environment.

\section{Conclusions}

Hot environment accelerated the death of hemorrhagic shock rats, which was related to the disorder of internal environment, increase of inflammatory and stress factors. Furthermore, moderate hypothermic fluid resuscitation was suitable for the treatment of hemorrhagic shock in hot environment.

\section{Background}

Shock is a syndrome caused by a variety of serious pathogenic factors, such as severe war (wound) injury, blood loss, infection, cardiac dysfunction and allergies, resulting in insufficient circulating blood volume, inadequate tissue perfusion, and organ dysfunction and even death [1]. The incidence and mortality of shock are very high both in peacetime and during war $[2,3]$. The incidence of traumatic shock in conventional warfare is $10-15 \%$, and the incidence of shock in future high-tech war can be as high as 
$25 \%-30 \%$ [4]. Organ function disorder is the main cause of later death after hemorrhagic shock [5]. A large number of relevant studies have been focused on the mechanism of organ injury caused by shock under room temperature environment and its prevention.

As the global environment changes, the environmental temperature gradually rises, and there are more and more people in areas with hot environment. Hot environment is also important for military operations in the world. Continuous hot environment will increase the core temperature of the body and cause heat stroke, which is a heat-related disease that seriously threatens human life. Severe heat stroke will cause central nervous system dysfunction, including epilepsy, coma and severe fever [6]. The number of deaths caused by heat stroke is increasing year by year [7]. Previous studies on the characteristics and treatment of shock are conducted in room temperature. It is not clear whether the hot environment can aggravate the organ function damage in hemorrhagic shock, and what is the mechanism and treatment.

Fluid resuscitation is an important treatment for patients with hemorrhagic shock, which can correct blood pressure and restore tissue perfusion and blood supply. For hemorrhagic shock in room temperature, resuscitation fluid should be kept warm to prevent lethal triad caused by cryogenic fluid resuscitation. But for hyperthermia patients whose core temperature rises, rapid cooling is the first measure of treatment. When heatstroke occurs, evacuate from the hot environment immediately to reduce the core temperature [8]. However, for patients suffering from hemorrhagic shock in hot environment, which temperature liquid is suitable is unclear.

To this aim, present study used a rat model of hemorrhagic shock in hot environment to explore the mechanism of organ function damage in rats and to find the efficacy of cryogenic fluid treatment. The main contents include: (1) the changes of organ function and survival suffering hemorrhagic shock in hot environment rats, and the pathophysiological mechanisms including internal environment, oxidative damage and inflammation; (2) The therapeutic effect of different temperatures of fluid on hemorrhagic shock in hot environment, which provides strategies for hemorrhagic shock in hot environment.

\section{Material And Methods}

\section{Animals model and protocols}

Sprague Dawley (SD) rats, weighing 180-220g, male. They were fasted for $12 \mathrm{~h}$, but allowed water ad libitum before experiments. Animals are kept in a room with a constant humidity of about $60 \%$, a temperature of $24^{\circ} \mathrm{C}$ and light $(06: 00-18: 00)$. Before the experiment, the rats were placed in a hot environment $\left(32^{\circ} \mathrm{C}, 34^{\circ} \mathrm{C}, 36^{\circ} \mathrm{C}\right.$ and $\left.38^{\circ} \mathrm{C}\right)$ for 12 hours, and the rats were anesthetized with pentobarbital sodium $(30 \mathrm{mg} / \mathrm{kg}$ ) and intubated. The right femoral artery was used to monitor blood pressure and bleeding, and the right carotid artery and neck intravenous cannula is used to measure cardiac function indicators. Bleeding was performed according to $40 \%$ of the whole blood volume, and the bleeding was completed within 1 hour. 
The experiment was divided into three parts, as shown in supplemental Fig. 1. Part I: The changes of rat core temperature and survival rate after shock in different temperature environment $\left(25^{\circ} \mathrm{C}, 32^{\circ} \mathrm{C}, 34^{\circ} \mathrm{C}\right.$, $36^{\circ} \mathrm{C}$ and $38^{\circ} \mathrm{C}$ ) were observed; Part $\rrbracket:$ The organ functions including cardiac, liver and kidney, internal

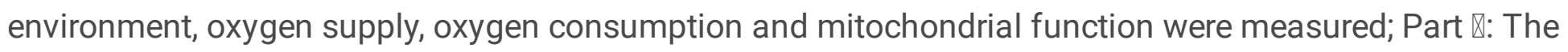
effects of fluid with different temperatures $\left(4^{\circ} \mathrm{C}, 10^{\circ} \mathrm{C}, 25^{\circ} \mathrm{C}\right.$ and $\left.37^{\circ} \mathrm{C}\right)$ on the core temperature and survival rate of rats in hyperthermia combination with hemorrhagic shock were further explored.

\section{The measurement of $\mathrm{CO} \square \mathrm{Cl} \square \mathrm{SI} \square \mathrm{DO}_{2} \llbracket \mathrm{VO}_{2}$}

The cardiac output of rats was measured by thermodilution method. The thermodilution catheter is inserted into the left ventricle through the right common carotid artery, while the jugular vein cannula is used to inject saline. The temperature and volume of the saline directly affect the determination of cardiac output. The injection temperature is automatically determined by a temperature probe, the injection volume of the rat is set to $0.3 \mathrm{ml}$, and the cardiac blood transfusion meter (Cardio MAX, model 0162-004M) is connected, cardiac output (CO) and heart rate (HR) are measured at each time point, and the formula is passed Calculate heart index: cardiac index $(\mathrm{Cl})=\mathrm{CO} \div$ body surface area $(\mathrm{S}), \mathrm{S}=\mathrm{K} \times \mathrm{W}^{2 / 3}$ $\left(\mathrm{cm}^{2}\right)$, where $\mathrm{K}=9.1 ; \mathrm{W}$ : weight $(\mathrm{g})[9]$ and stroke index $(\mathrm{SI})=\mathrm{Cl} \div \mathrm{HR}$. Use a blood gas analyzer (Phox plus $\mathrm{L}$, Nova biomedical) to measure arterial blood gas [ partial pressure of oxygen $\left(\mathrm{PaO}_{2}\right)$, arterial blood oxygen saturation $\left(\mathrm{SaO}_{2}\right)$, bicarbonate $\left(\mathrm{HCO}^{-}\right)$, alkali excess $\left.(\mathrm{BE})\right]$ and venous blood gas [Venous oxygen saturation $\left(\mathrm{SvO}_{2}\right)$ and hemoglobin $(\mathrm{Hb})$ ], calculate tissue oxygen supply $\left(\mathrm{DO}_{2}=\mathrm{Cl} \times 13.4 \times \mathrm{Hb} \times\right.$ $\left.\mathrm{SaO}_{2}\right)$ and tissue oxygen consumption $\left[\mathrm{VO}_{2}=\mathrm{Cl} \times 13.4 \times \mathrm{Hb} \times\left(\mathrm{SaO}_{2}-\mathrm{SvO}_{2}\right)\right]$ [10]. The unit of $\mathrm{CO}$ is $\mathrm{L} / \mathrm{min}$, the unit of $\mathrm{Cl}$ is $\mathrm{L} / \mathrm{min} \cdot \mathrm{m}^{2}$, and the unit of $\mathrm{SI}$ is $\mathrm{L} / \mathrm{min} \cdot \mathrm{m}^{2}$.

\section{The measurement of ATP content}

Tissue sample preparation: add $150 \mu \mathrm{L}$ of lysis buffer per $20 \mathrm{mg}$ tissue, homogenize and lyse thoroughly, centrifuge at $4^{\circ} \mathrm{C} \times 12000 \mathrm{~g} \times 5 \mathrm{~min}$, and take the supernatant. Make a standard curve: adenosinetriphosphate triphosphate (ATP) standard solution is diluted with ATP lysis solution to a series of concentrations of $0.01,0.03,0.1,0.3,1,3$, and $10 \mu \mathrm{mol} / \mathrm{L}$, and the standard curve is drawn. ATP detection working solution: add $100 \mu \mathrm{L}$ of ATP working solution to each sample, take an appropriate amount of ATP detection reagent, and dilute the ATP detection reagent 1:9. The diluted ATP detection reagent is the ATP detection working solution for subsequent experiments. Determination of ATP concentration: Add 100 $\mu \mathrm{L}$ of ATP detection working solution to the detection hole or detection tube, and leave it at room temperature for 3-5 minutes to consume all the background ATP, thereby reducing the background. Add $20 \mu \mathrm{L}$ of sample or standard to the test hole or test tube, and quickly mix it with a pipette. After an interval of at least $2 \mathrm{~s}$, use a luminometer or liquid scintillation meter to determine the RLU value or CPM. Calculate the concentration of ATP in the sample according to the standard curve. The BCA protein concentration determination kit produced by Beyotime biotechnology was used to determine the protein concentration in the sample. Convert the concentration of ATP to $\mathrm{nmol} / \mathrm{mg}$.

\section{Determination of stress factors, inflammatory factors and oxidative stress factors}


Stress factor was measured using adrenocortical hormone (ACTH) kit (catalog no. F15031; Xi tang Biotechnology Company, China) and Glucocorticoid (GCS) kit (catalog no. F15485; Xi tang Biotechnology Company, China); inflammatory factor was measured using interleukin-6 (IL-6) (catalog no. F15870; Xi tang Biotechnology Company, China) and tumor necrosis factor-a (TNF-a) kit (catalog no. F16960; Xi tang Biotechnology Company, China); oxidative stress was measured using reactive oxygen species (ROS) (catalog no. E004; Nanjing Jiancheng Technology Company, China) and malondialdehyde (MDA) (catalog no. A003-1; Nanjing Jiancheng Technology Company, China)

\section{The observation of electrolytes, osmotic pressure and other parameters}

Electrolytes $\left(\mathrm{Na}^{+}, \mathrm{K}^{+}\right)$, OSM, liver function [aspartate transaminase (AST) and alanine aminotransferase $(A L T)$ ] and kidney function [urea nitrogen (BUN) and creatinine (Crea)] were used with a fully automatic biochemical analyzer (DX800; Beckman Coulter, Fullerton, CA), and the blood sample volume was $2 \mathrm{~mL}$.

\section{Statistical analysis}

Data are the mean \pm SD of n observations. Statistical differences were analyzed by a repeated measures one-way or two-way ANOVA followed by the post hoc Tukey test (SPSS13.0; SPSS Incorporated, Chicago, IL). Survival time and survival rate were analyzed by median and interquartile range and Kaplan - Meier survival analysis and log-rank test. A P value less than 0.05 was considered significant (two-tailed).

\section{Results}

\section{The hot environment increased hemorrhagic shock induced death in rats}

\section{Body core temperature}

In order to observe the effect of different temperature environment, the rats were placed in environmental boxes with different temperatures of hot environment, including $32^{\circ} \mathrm{C}, 34^{\circ} \mathrm{C}, 36^{\circ} \mathrm{C}, 38^{\circ} \mathrm{C}$, and $25^{\circ} \mathrm{C}$ was designated as control group of room temperature environment. The anus temperature of the rats was measured every $0.5 \mathrm{~h}$ for $12 \mathrm{~h}$ from the beginning of the placement. The results showed that in different temperature environment, the changes in the core temperature of rats were obvious different. In the environment at $36^{\circ} \mathrm{C}$ and $38^{\circ} \mathrm{C}$, the core temperature of the rat began to rise within 30 minutes, and the core temperature rose to $40.1^{\circ} \mathrm{C}$ within 30 minutes in $38^{\circ} \mathrm{C}$ environment and reached the maximum in 2 hours to $40.5^{\circ} \mathrm{C}$, maintained a fluctuation between $39.8^{\circ} \mathrm{C}$ and $40.5^{\circ} \mathrm{C}$; the change in the $36^{\circ} \mathrm{C}$ environment was similar to the $38^{\circ} \mathrm{C}$ environment, the maximum core temperature was $39.9^{\circ} \mathrm{C}$. In $34^{\circ} \mathrm{C}$ environment, the core temperature of rats was slightly increased within 30 min, maintained at $39.2^{\circ} \mathrm{C}$ for $3 \mathrm{~h}$, and then returned to the normal range from $38.6^{\circ} \mathrm{C}$ to $38.9^{\circ} \mathrm{C}$. In $32^{\circ} \mathrm{C}$ environment, the core temperature of rats was not obviously increased and maintained at normal level which was similar to that in room temperature environment $\left(25^{\circ} \mathrm{C}\right)$ between $38.6^{\circ} \mathrm{C}$ and $38.8^{\circ} \mathrm{C}$ (Fig. 1a). The results indicate 
that the core temperature will increase when the ambient temperature is higher than $36^{\circ} \mathrm{C}, 34^{\circ} \mathrm{C}$ environment does not lead to the increase of the core temperature.

\section{Survival rate and survival time}

In order to observe the influence of hot environment on hemorrhagic shock, the rats were placed in different temperature environment $\left(25^{\circ} \mathrm{C}, 32^{\circ} \mathrm{C}, 34^{\circ} \mathrm{C}, 36^{\circ} \mathrm{C}\right.$ and $\left.38^{\circ} \mathrm{C}\right)$ for 12 hours, and then $40 \%$ blood loss was performed, and survival time and survival rate in rat were observed. The results showed that in room temperature environment, the 12-hour survival rate of rats was $87.5 \%(14 / 16)$ following $40 \%$ hemorrhagic shock, and the average survival time was $(11.1 \pm 2.6) \mathrm{h} ; 36^{\circ} \mathrm{C}$ and $38^{\circ} \mathrm{C}$ environment which caused the core temperature rising significantly aggravated hemorrhagic shock induced death, the 12hour survival rates at $36^{\circ} \mathrm{C}$ and $38^{\circ} \mathrm{C}$ were $6.3 \%(1 / 16)$ and $0 \%(0 / 16)$, respectively, the average survival time were $(1.5 \pm 2.9) \mathrm{h}$ and $(0.53 \pm 0.44) \mathrm{h}$, respectively. And results also showed that even in the $34^{\circ} \mathrm{C}$ and $32^{\circ} \mathrm{C}$ environment where the core temperature was not obvious increased, the survival rate of rats was also significantly reduced after hemorrhagic shock as compared with room temperature environment, the 12-hour survival rate was $75 \%(12 / 16)\left(32^{\circ} \mathrm{C}\right.$ environment) and $31.3 \%(5 / 16)\left(34^{\circ} \mathrm{C}\right.$ environment), the survival time was $(9.4 \pm 4.6) \mathrm{h}$ and $(4.5 \pm 5.4) \mathrm{h}$, respectively (Fig. $1 \mathrm{~b}-\mathrm{c})$. The results indicate that hot environment aggravates hemorrhagic shock-induced death of rats. The $34^{\circ} \mathrm{C}$ environment does not increase core temperature; however, it aggravates hemorrhagic shock - induced injury; in the follow-up study, hemorrhagic shock in $34^{\circ} \mathrm{C}$ environment was used to further explore organ function and pathophysiologic mechanisms.

\section{Hot environment aggravated hemorrhagic shock-induced organ function damage in rats}

The dysfunction of the heart, liver, and kidney is very important for the occurrence and development of hemorrhagic shock. The changes of vital organ function were observed with hemorrhagic shock in $34^{\circ} \mathrm{C}$ hot environment. The results showed that hemorrhagic shock led to vital organ function injury in room temperature environment similar with previous studies. It was showed that $\mathrm{CO}, \mathrm{Cl}$ and $\mathrm{SI}$ was decreased and AST, ALT (liver damage parameter), BUN, Crea (kidney damage parameter) were increased significantly. And vital organ function of rats was not obvious injury in the $34^{\circ} \mathrm{C}$ hot environment for 12 hours without hemorrhagic shock; while the organ function damage was aggravated significantly after hemorrhagic shock in the hot environment. As compared with normal environment hemorrhagic shock, which was manifested in a further decrease of $\mathrm{CO}, \mathrm{Cl}$ and $\mathrm{SI}$, and the increases of AST, ALT, BUN and Crea. In room temperature environment, hemorrhagic shock induced decrease ratios were $57.7 \%, 57.0 \%$, and $56.5 \%$ in $\mathrm{CO}, \mathrm{Cl}, \mathrm{SI}$ respectively; in $34^{\circ} \mathrm{C}$ hot environment, the decrease ratios were $64.9 \%, 65.0 \%$ and $66.5 \%$ in $\mathrm{CO}, \mathrm{Cl}, \mathrm{SI}$ respectively. The changes of liver and kidney function were similar with heart function, hot environment could further increase the hemorrhagic shock induced the increased of AST, ALT, BUN and Crea. The results indicate that hot environment aggravates hemorrhagic shock-induced organ function damage as compared with room temperature environment. (Fig. 2) 
Changes of internal environment, inflammatory factors and stress response with hemorrhagic shock rats in hot environment

\section{Changes of the internal environment}

Previous studies found that heat stroke caused by high fever would lead to electrolyte disturbances, which were mainly manifested as hyponatremia, hypokalemia, hyperchloremia, and high plasma osmotic pressure [11]. The change of these parameters was investigated following hemorrhagic shock in $34^{\circ} \mathrm{C}$ hot environment. The results showed that the concentration of $\mathrm{Na}^{+}$concentration in the plasma of rats was increased significantly, and the changes in $\mathrm{K}^{+}$concentration and OSM were not obvious in rats being placed at $34^{\circ} \mathrm{C}$ for $12 \mathrm{~h}$ without hemorrhagic shock; After hemorrhagic shock, the concentration of $\mathrm{Na}^{+}$ concentration, $\mathrm{K}^{+}$concentration and OSM were significantly increased in rats from $34^{\circ} \mathrm{C}$ hot environment. (Fig. 3a-c)

\section{Changes of inflammatory factors}

Inflammation was an important pathophysiological mechanism induced organ dysfunction after hemorrhagic shock [12]. Whether levels of inflammatory factor will be further increased in hot environment is not clear. The results showed that $34^{\circ} \mathrm{C}$ hot environment for $12 \mathrm{~h}$ without hemorrhagic shock did not lead to the increase of the inflammatory factors including TNF-a and IL-6 in rats. Similar with previous reports, the levels of serum TNF-a and IL- 6 were increased following hemorrhagic shock at room temperature environment, they were $50.2 \%$ and $35.5 \%$ higher than without hemorrhagic shock. $34{ }^{\circ} \mathrm{C}$ hot environment led to further increase of levels of TNF-a and IL- 6 in rats, they were $62.1 \%$ and $54.1 \%$ higher than without shock, respectively. (Fig. 3d-e)

\section{Changes in stress response}

Stress response is the normal response of the body to external stimuli, excessive stress response, including the over increase of ACTH and GCS, does not play a protective role, while damages the body function. Present study was to further measure the changes of stress factors in rats with hemorrhagic shock in hot environment. The results showed that similar with previous study, hemorrhagic shock increased the levels of ACTH and GCS in rats in room temperature environment. $34^{\circ} \mathrm{C}$ hot environment without hemorrhagic shock induced the significant increase of ACTH and GCS. $34^{\circ} \mathrm{C}$ hot environment further increased hemorrhagic shock induced the increase of ACTH and GCS, the levels of ACTH and GCS reached to $9.88 \mu \mathrm{g} / \mathrm{mL}$ and $241.45 \mathrm{pg} / \mathrm{mL}$ respectively (Fig. $3 f-g$ ).

Changes of blood gas, tissue oxygen delivery, oxygen consumption and mitochondrial function in rats following hemorrhagic shock in hot environment

\section{Changes of blood gas}

$34^{\circ} \mathrm{C}$ hot environment without hemorrhagic shock did not cause significant changes in blood gas. Values of Lac were increased in rats after hemorrhagic shock in room temperature environment. $34^{\circ} \mathrm{C}$ hot 
environment significantly aggravated hemorrhagic shock induced the changes of blood gas, it was shown the increase of Lac and decrease of $\mathrm{PO}_{2}$ and $\mathrm{PCO}_{2}(\mathrm{P}<0.01$, supplementary Table 1$)$.

\section{Changes of tissue oxygen delivery and oxygen consumption}

Oxygen supply and oxygen consumption are the main factors affecting tissue and cell metabolism. The results showed that without hemorrhagic shock, the $\mathrm{MAP}, \mathrm{DO}_{2}$ and $\mathrm{VO}_{2}$ of rats in $34^{\circ} \mathrm{C}$ hot environment were similar with room temperature environment. Hemorrhagic shock in room temperature environment resulted in the decrease of the $\mathrm{MAP}, \mathrm{DO}_{2}$ and $\mathrm{VO}_{2}$, and $1 \mathrm{~h}$ after hemorrhagic shock, they were decreased to $32.0 \%, 39.8 \%$, and $55.2 \%$ respectively as compared with without hemorrhagic shock. $\mathrm{MAP}_{2} \mathrm{DO}_{2}$ and $\mathrm{VO}_{2}$ were further decreased in $34^{\circ} \mathrm{C}$ hot environment after hemorrhagic shock, they were decreased to $28.4 \%, 31.7 \%$, and $39.6 \%$ of the normal level. (Fig. $4 a-c$ )

\section{Changes in mitochondrial function}

Mitochondria function determines the organ function, mitochondrial dysfunction is related to outcome of shock [13]. In this part, the mitochondrial functions including ATP content, Na-K ATPase activity, Ca-Mg ATPase activity and Ca ATPase activity were explored. The results showed that without hemorrhagic shock, there were no significant changes including ATP content, Na-K ATPase activity, Ca-Mg ATPase activity and Ca ATPase activity in cardiac tissue between hot environment and room temperature environment; after hemorrhagic shock, the ATP content, Na-K ATPase activity, Ca-Mg ATPase activity and Ca ATPase activity were significantly decreased in room temperature environment; $34^{\circ} \mathrm{C}$ hot environment further aggravated the decrease of hemorrhagic shock induced the decrease of ATP content, Na-K ATPase activity, Ca-Mg ATPase activity and Ca ATPase activity. Compared with the pre-shock, they were decreased by $59.2 \%, 32.6 \%, 33.0 \%$ and $25.8 \%$ respectively $1 \mathrm{~h}$ after hemorrhagic shock (Fig. $4 \mathrm{~d}-\mathrm{g}$ ).

Mitochondria are the main source of ROS. ROS and MDA also reflect mitochondrial functions. The results showed that without hemorrhagic shock, ROS and MDA were similar in $34^{\circ} \mathrm{C}$ hot environment and room temperature environment; Following hemorrhagic shock, ROS and MDA were increased significantly both in normal and $34^{\circ} \mathrm{C}$ hot environment, but the increase degrees of ROS and MDA in $34^{\circ} \mathrm{C}$ hot environment were more, and ROS and MDA were increased by $57.4 \%$ and $40.8 \%$ respectively $1 \mathrm{~h}$ after hemorrhagic shock (Fig. 4h-i).

\section{The resuscitation effect of different temperature fluid following hemorrhagic shock in hot environment}

Fluid resuscitation is vital treatment for hemorrhagic shock. Whether low temperature fluid is suitable for the hot environment and hemorrhagic shock rats is not clear. After the rats were placed in a hot environment $\left(34^{\circ} \mathrm{C}\right)$ for $12 \mathrm{~h}$, and $40 \%$ blood loss to establish hemorrhagic shock model. Lactated Ringer's solution (LR) with different temperatures $\left(37^{\circ} \mathrm{C}, 25^{\circ} \mathrm{C}, 10^{\circ} \mathrm{C}, 4^{\circ} \mathrm{C}\right)$ was administrated, the 72 -hour survival time and survival rate were observed. The results showed that the core temperature of rats at the end of hemorrhagic shock was $38.4 \pm 0.4^{\circ} \mathrm{C}$, following LR resuscitation at different temperatures 
including $4^{\circ} \mathrm{C}, 10^{\circ} \mathrm{C}, 25^{\circ} \mathrm{C}$ and $37^{\circ} \mathrm{C}$, the core temperature of rats was different. They were $36.2 \pm 0.6^{\circ} \mathrm{C}$, $36.5 \pm 0.4^{\circ} \mathrm{C}, 37.2 \pm 0.6^{\circ} \mathrm{C}, 37.9 \pm 0.4^{\circ} \mathrm{C}$, respectively. (Fig. $5 \mathrm{a}$ )

LR resuscitation with different temperature could prolong the survival time and survival rate of rats. With the fluid temperature decrease, the survival rate and survival time of rats were increased, but when the temperature of the resuscitation fluid was too low, the survival of the rats was decreased. After resuscitation with $4^{\circ} \mathrm{CLR}, 10^{\circ} \mathrm{CLR}, 25^{\circ} \mathrm{CLR}$, and $37^{\circ} \mathrm{CLR}$, the survival rates were $62.5 \%$ (P凶0.05), $81.3 \%$, $43.8 \%$ and $25.0 \%$, respectively, and their survival time were $49.4 \pm 30.2 \mathrm{~h}, 58.4 \pm 24.5 \mathrm{~h}, 36.9 \pm 32.0 \mathrm{~h}, 21.7 \pm$ $30.1 \mathrm{~h}$, respectively (Fig. $5 \mathrm{~b}-\mathrm{C}$ ). $10^{\circ} \mathrm{C}$ LR resuscitation had best effect. The above results indicate that moderate low temperature resuscitation fluid was suitable for treatment of hemorrhagic shock in hot environment.

\section{Discussion}

Hemorrhagic shock is a syndrome of cell hypoxia, metabolic disorders and organ function damage caused by massive blood loss. The main manifestations are insufficient effective circulating blood volume and insufficient tissue perfusion $[1,3]$. Shock has a high incidence in battlefields and daily traffic accidents, and is the main cause of death in patients due to blood loss. Heat shock is caused by excessively long time in a hot environment, and it is a clinical emergency symptom characterized by damage of circulatory system and nervous system function [6]. The current mainly focuses on the research about the related mechanism and prevention of hemorrhagic shock and heat shock in room temperature environment. Influence of hot environment on hemorrhagic shock induced organ function and its pathophysiological mechanisms and treatment are unclear.

Present study found that above $36^{\circ} \mathrm{C}$ of hot environment could cause significant increase of core body temperature, and below $34^{\circ} \mathrm{C}$ of hot environment did not induce an increase of core body temperature, but it could still aggravate hemorrhagic shock induced the mortality. Further studies showed that without hemorrhagic shock, the $34^{\circ} \mathrm{C}$ hot environment did not cause obvious changes in the pathophysiological indicators of rats; while following hemorrhagic shock, the $34^{\circ} \mathrm{C}$ hot environment aggravated significantly hemorrhagic shock induced organ function disorder, and increased internal environmental disturbances and stress factors and inflammatory factors, and exacerbated the damage of mitochondrial function, tissue oxygen supply and oxygen consumption, and the survival time of rats in hot environment after hemorrhagic shock was significantly shortened. Further study showed that moderate hypothermia $\left(4^{\circ} \mathrm{C}-10^{\circ} \mathrm{C}\right) \mathrm{LR}$ resuscitation was suitable for hemorrhagic shock treatment in hot environment. This study provided a suitable strategy for hemorrhagic shock in hot environment.

Previous studies about high temperature environment mainly focused on the disorder of body temperature regulation mechanism caused by ambient temperature above $40^{\circ} \mathrm{C}$, which resulted in the occurrence of central nervous system abnormalities, and progressive multiple organ function damage [6]. It was manifested as disturbance of consciousness, liver and kidney failure, disseminated intravascular coagulation, cardiac failure, rhabdomyolysis, etc. Severe heatstroke would lead to multiple organ 
dysfunction and death. For example, Proctor and other studies found that when mice were exposed to $39.5^{\circ} \mathrm{C}$ would cause coagulation dysfunction [14]; Zhou et al. found that when rats were exposed to a simulated desert environment $\left(41^{\circ} \mathrm{C}\right)$, the liver (AST, ALT), kidney (BUN, Crea), heart (CK-MB, CK kinase) and lung function (BEecf, $\mathrm{HCO}^{-}$) were significantly damaged. At the same time, the morphology and structure of liver, kidney, heart, and lungs were changed significantly after heatstroke, and as the duration of heatstroke prolong, the damage to organ function was aggravated [15]. Studies also found that placing intestinal epithelial cells at $42^{\circ} \mathrm{C}$ for 1 hour would produce excessive ROS and increase cell permeability [16]. Present study discovered that the changes of organ function, inflammatory response and stress factors were not obvious in $34^{\circ} \mathrm{C}$ hot environment which did not cause core temperature to rise, but it would significantly aggravate hemorrhagic shock induced the internal environment disorder and inflammatory response, aggravate organ function damage and significantly shorten the survival time of rats. The results indicate that even the core temperature does not increase in a mild hot environment, the treatment of patients should be strengthened after hemorrhagic shock.

Present study found that the internal environment and stress level of rats was not changed significantly in the $34^{\circ} \mathrm{C}$ hot environment. However, when combination with hemorrhagic shock, the internal environment disorder and stress response of rats were significantly stronger than that of hemorrhagic shock alone, which may be related to the adaptability of the body. In the $34^{\circ} \mathrm{Cenvironment,} \mathrm{although} \mathrm{the}$ core temperature of rats was not increased significantly, the high metabolic state caused by hot environment, the increase of heat dissipation in order to maintain normal core temperature, could lead to high consumption of rats. When suffering from hemorrhagic shock again, the body's compensatory ability had been exhausted, resulting in excessive stress and electrolyte decompensation. Dematte found that the incidence of infection was higher in patients with heatstroke. After heatstroke, the inflammatory factors in plasma including TNF-a, IL-1 $\beta$ and IFN- $\gamma$ were increased significantly, which caused systemic and local damage in rats and rabbits [17]. In addition, studies found that in animal and human heatstroke models, local and systemic injuries related to heat stress, such as insufficient visceral perfusion, would change the nutrition and barrier function of the intestine. This change caused endotoxins to be released into the blood circulation, causing an increase in inflammatory factors (such as excessive activation of IL-1 and IL-6) [6]. Present research found that there was no obvious change in inflammatory factors TNF$a$ and IL- 6 in $34^{\circ} \mathrm{C}$ hot environment. When combined with hemorrhagic shock, the inflammatory response induced by high temperature was more serious. The reason may be that high temperature aggravated the damage of intestinal mucosa caused by hemorrhagic shock, further increased intestinal permeability, and released endotoxin into the blood circulation, thus aggravating the inflammatory response. The specific mechanism needs to be further studied.

Previous studies had shown that heatstroke could cause mitochondrial dysfunction and inactivation of enzymes [18-19]. As we know, mitochondria are ubiquitous bilayer membrane structures in eukaryotes, mainly involved in ATP production, oxidative phosphorylation and oxygen sensing. Oxygen consumption rate (OCR) is an indicator of mitochondrial respiration. Under physiological conditions, the difference between basic respiration and maximum respiration is spare respiratory capacity [20]. In present study, 
the mitochondrial function of rats in hot environment was not significantly damaged, including ATP content, Na-K ATPase activity, Ca-Mg ATPase activity and Ca-ATPase activity were not significantly decreased, hyperthermia aggravated hemorrhagic shock induced the mitochondrial function damage in rats, ATP content, Na-K ATPase activity, Ca-Mg ATPase activity and Ca ATPase activity were significantly decreased, ROS and MDA was increased significantly. The reason may be that hot environment produce stress response and make use of the spare respiratory capacity to compensate for the effect of high fever; when high fever is accompanied with hemorrhagic shock, the body appears to be decompensated, the basic and maximum respiration are decreased, the spare respiratory capacity is exhausted, and the normal mitochondrial function is no longer maintained, resulting in mitochondrial dysfunction. It is an important cause of organ function damage and accelerated death of rats. However, the specific mechanism needs to be further studied.

Fluid resuscitation is the first measure for the early treatment of hemorrhagic shock. After hemorrhagic shock in a room temperature environment, low temperature fluid is not recommended in order to avoid complications such as the fatal triad caused by hypothermia. While present study demonstrated that mild low temperature fluid administration is suitable for hemorrhagic shock in hot environment. The reason may be that intravenous infusion of cryogenic fluid can not only lower the core temperature, but also supplement the insufficient blood volume caused by blood loss. Hostler et al showed that hypothermic saline infusion can lower the core temperature of awake or anesthetized subjects [21]. Frank et al found that when $4^{\circ} \mathrm{C}$ normal saline was infused to healthy adults without underlying diseases, their core temperature dropped by $1^{\circ} \mathrm{C}$ [22]. Further studies found that the decrease in core temperature increased the activity of peripheral sympathetic nerves and increased the concentration of norepinephrine, which makes blood vessels constrict and blood pressure rises. The specific mechanism needs to be further studied.

Although present study found that the hot environment aggravated the internal environment disorder, mitochondrial dysfunction and organ function damage in hemorrhagic shock rats, there were still some shortcomings: only $34^{\circ} \mathrm{C}$ environmental temperature was observed, and the pathophysiological characteristics and damage mechanism of hemorrhagic shock under higher temperature environment such as $36^{\circ} \mathrm{C}$ and $38^{\circ} \mathrm{C}$ need to be further studied; $4-10^{\circ} \mathrm{C} \mathrm{LR}$ resuscitation is beneficial to the survival of rats with hemorrhagic shock in hot environment, but the specific application temperature, dosage and maintenance time need to be studied in detail.

\section{Conclusions}

Hot environment aggravates the death of rats with hemorrhagic shock, and the higher the ambient temperature, the faster the death; high temperature (the core temperature remains unchanged) lead to the rapid death of hemorrhagic shock, which may be related to the damage of myocardial mitochondrial function and the damage of organ function due to high temperature; Mild cryogenic fluid can improve the survival of rats with hemorrhagic shock in hot environment. 


\section{Abbreviations}

SD: Sprague Dawley; CO: cardiac output; HR: heart rate; Cl: cardiac index; S: body surface area; SI: stroke index; $\mathrm{PaO}_{2}$ : partial pressure of oxygen; $\mathrm{SaO}_{2}$ : arterial blood oxygen saturation; $\mathrm{HCO}^{-}$: bicarbonate; $\mathrm{BE}$ : alkali excess; $\mathrm{SvO}_{2}$ : Venous oxygen saturation; $\mathrm{Hb}$ : hemoglobin; $\mathrm{DO}_{2}$ : tissue oxygen supply; $\mathrm{VO}_{2}$ : tissue oxygen consumption; ATP: adenosine-triphosphate triphosphate; ACTH: adrenocortical hormone; GCS: Glucocorticoid; IL-6: interleukin-6; TNF-a: tumor necrosis factor-a; ROS: reactive oxygen species; MDA: malondialdehyde; AST: aspartate transaminase; ALT: alanine aminotransferase; BUN: urea nitrogen; Crea: creatinine; OCR: Oxygen consumption rate.

\section{Declarations}

\section{Ethics approval}

The research was approved by the Institute of Field Surgery and Animal Management Committee of Daping Hospital, Army Medical University. This research animal experiment complies with the guidelines for the management and use of laboratory animals published by the National Institutes of Health (Eighth Edition, 2011; National Institutes of Health, Bethesda, MD).

\section{Consent for publication}

Not applicable.

\section{Availability of data and materials}

All materials are commercially available, and the datasets used and/or analyzed during the current study are available from the corresponding author on reasonable request.

\section{Competing interests}

There is no competing conflict of interest for this study.

\section{Funding}

This work was supported by the Key Research Projects of Military Logistics of China (grant numbers BLJ19J008); Military Medicine Frontier Innovation Capability Training Program of China (grant numbers 2019CXJSC017).

\section{Authors' contributions}

ZY, MS and TKL carried out the experiments, ZJ, SH collected and analyzed the data, ZY and DHY drafted the manuscript. LT and LLM conceived the study, participated its design and coordination, and edited the manuscript. All authors read and approved the version of the manuscript. 


\section{Acknowledgments}

We are grateful to ZHL for the help in providing environment box. Thank WL for helpful discussion. The authors thank Dr. ZDY for critical reading of the article and provide language help.

\section{References}

1. Cannon JW. Hemorrhagic Shock. N Engl J Med. 2018;378(4):370-379.

2. Mahambrey T, Pendry K, Nee A, Bonney S, Nee PA. Critical care in emergency department: massive haemorrhage in trauma. Emergency medicine journal : EMJ. 2013;30(1):9-14.

3. Liu L, Tian K, Zhu Y, Ding X, Li T. $\delta$ opioid receptor antagonist, ICI 174,864, is suitable for the early treatment of uncontrolled hemorrhagic shock in rats. Anesthesiology. 2013;119(2):379-88.

4. Liu L, Tian K, Xue M, Zhu Y, Lan D, Peng X, et al. Small doses of arginine vasopressin in combination with norepinephrine "buy" time for definitive treatment for uncontrolled hemorrhagic shock in rats. Shock (Augusta, Ga). 2013;40(5):398-406.

5. Cannon JW. Hemorrhagic Shock. The New England journal of medicine. 2018;378(4):370-9.

6. Bouchama A, Knochel JP. Heat stroke. The New England journal of medicine. 2002;346(25):1978-88.

7. Hsi-Hsing Y, Ching-Ping C, Juei-Tang C, Lin MT. Inhibition of acute lung inflammation and injury is a target of brain cooling after heatstroke injury. The Journal of trauma. 2010;69(4):805-12.

8. Gaudio FG, Grissom CK. Cooling Methods in Heat Stroke. The Journal of emergency medicine. 2016;50(4):607-16.

9. Holt JP, Rhode EA, Kines H. Ventricular volumes and body weight in mammals. The American journal of physiology. 1968;215(3):704-15.

10. Zhu Y, Wu H, Wu Y, Zhang J, Peng X, Zang J, et al. Beneficial Effect of Intermedin 1-53 in Septic Shock Rats: Contributions of Rho Kinase and BKCA Pathway-Mediated Improvement in Cardiac Function. Shock (Augusta, Ga). 2016;46(5):557-65.

11. Satirapoj B, Kongthaworn S, Choovichian P, Supasyndh O. Electrolyte disturbances and risk factors of acute kidney injury patients receiving dialysis in exertional heat stroke. BMC nephrology. 2016;17(1):55.

12. McGhan LJ, Jaroszewski DE. The role of toll-like receptor-4 in the development of multi-organ failure following traumatic haemorrhagic shock and resuscitation. Injury. 2012;43(2):129-36.

13. Annesley SJ, Fisher PR. Mitochondria in Health and Disease. Cells. 2019;8(7).

14. Proctor EA, Dineen SM, Van Nostrand SC, Kuhn MK, Barrett CD, Brubaker DK, et al. Coagulopathy signature precedes and predicts severity of end-organ heat stroke pathology in a mouse model. Journal of thrombosis and haemostasis. 2020;18(8):1900-10.

15. ou Zhou R, Liu JW, Zhang D, Zhang Q. Heatstroke model for desert dry-heat environment and observed organ damage. The American journal of emergency medicine. 2014;32(6):573-9. 
16. Liu Y, Wang Z, Xie W, Gu Z, Xu Q, Su L. Oxidative stress regulates mitogen-activated protein kinases and c-Jun activation involved in heat stress and lipopolysaccharide-induced intestinal epithelial cell apoptosis. Molecular medicine reports. 2017;16(3):2579-87.

17. Dematte JE, O'Mara K, Buescher J, Whitney CG, Forsythe S, McNamee T, et al. Near-fatal heat stroke during the 1995 heat wave in Chicago. Annals of internal medicine. 1998;129(3):173-81.

18. Huang C, Jiao H, Song Z, Zhao J, Wang X, Lin H. Heat stress impairs mitochondria functions and induces oxidative injury in broiler chickens. Journal of animal science. 2015;93(5):2144-53.

19. Radaković S, Marić J, Surbatović M, Vasiljević N, Milivojević M. Influence of acclimatization on serum enzyme changes in soldiers during exertional heat stress. Vojnosanitetski pregled. 2009;66(5):359-64.

20. Sure VN, Sakamuri S, Sperling JA, Evans WR, Merdzo I, Mostany R, et al. A novel high-throughput assay for respiration in isolated brain microvessels reveals impaired mitochondrial function in the aged mice. GeroScience. 2018;40(4):365-75.

21. Hostler D, Northington WE, Callaway CW. High-dose diazepam facilitates core cooling during cold saline infusion in healthy volunteers. Applied physiology nutrition and metabolism. 2009;34(4):5826.

22. Frank SM, Higgins MS, Fleisher LA, Sitzmann JV, Raff H, Breslow MJ. Adrenergic, respiratory, and cardiovascular effects of core cooling in humans. The American journal of physiology. 1997;272(2):R557-62.

\section{Figures}


a

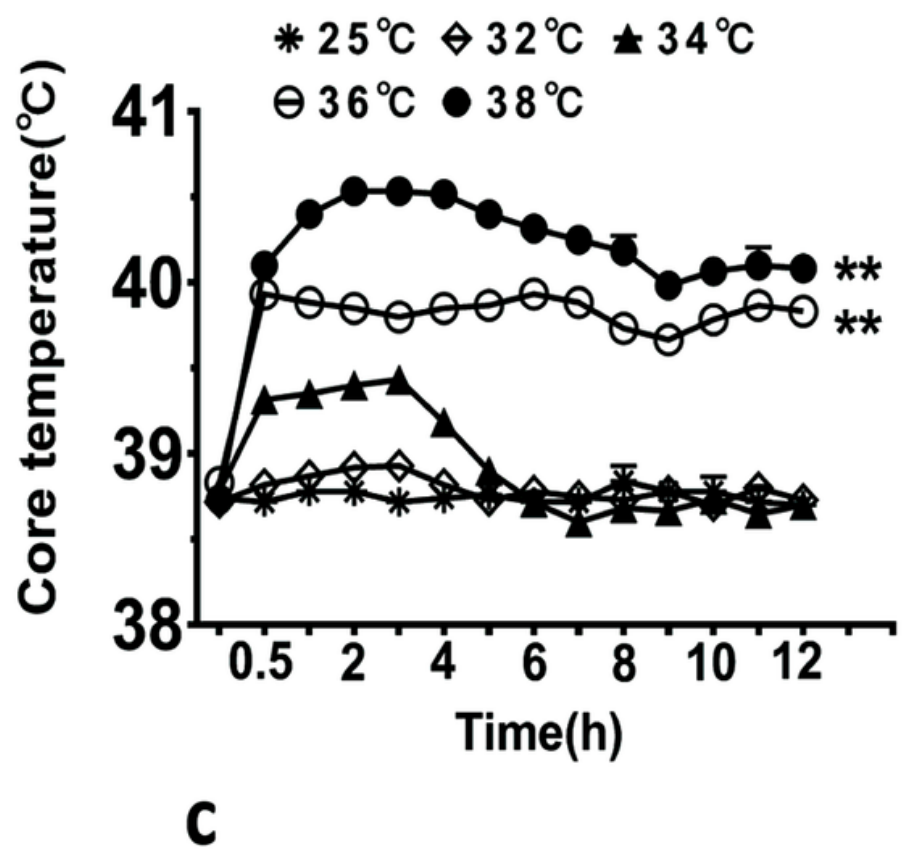

b

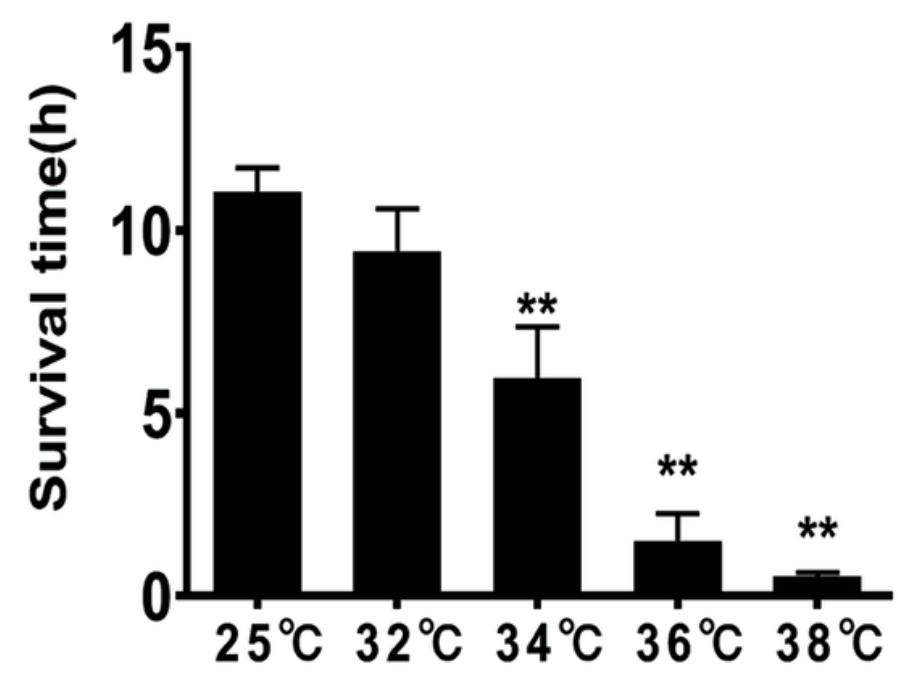

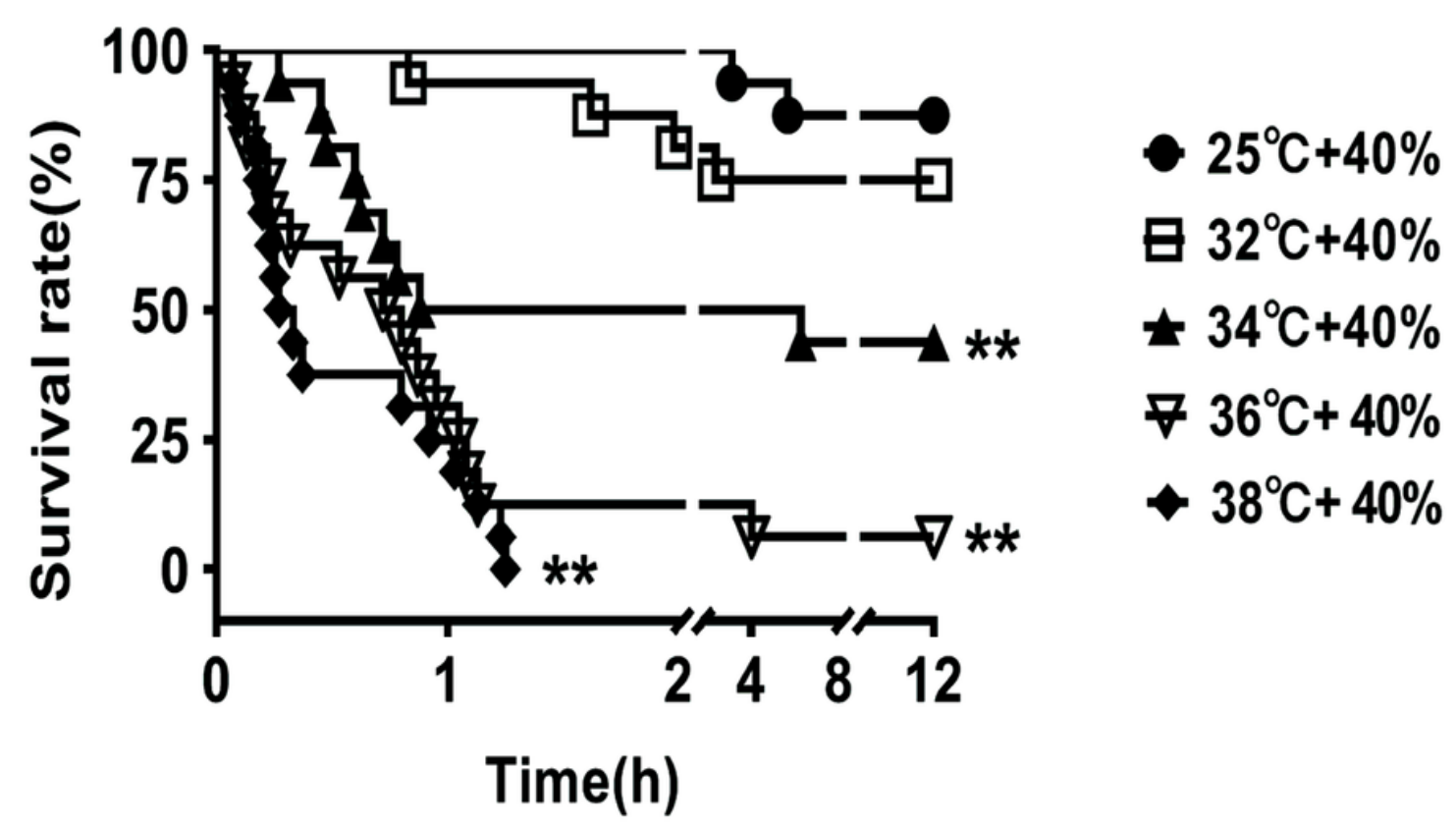

Figure 1

Effects of different temperature environment on the core temperature of rats and changes in survival time and survival rate of rats following hemorrhagic shock in hot environment. $* * \mathrm{P} \otimes 0.01$, compared with the room temperature group $\left(25^{\circ} \mathrm{C}\right)$. a: core temperature; b: survival rate; c: survival time. ${ }^{\star * P} \otimes 0.01$, compared with room temperature group $\left(25^{\circ} \mathrm{C}\right)$. 

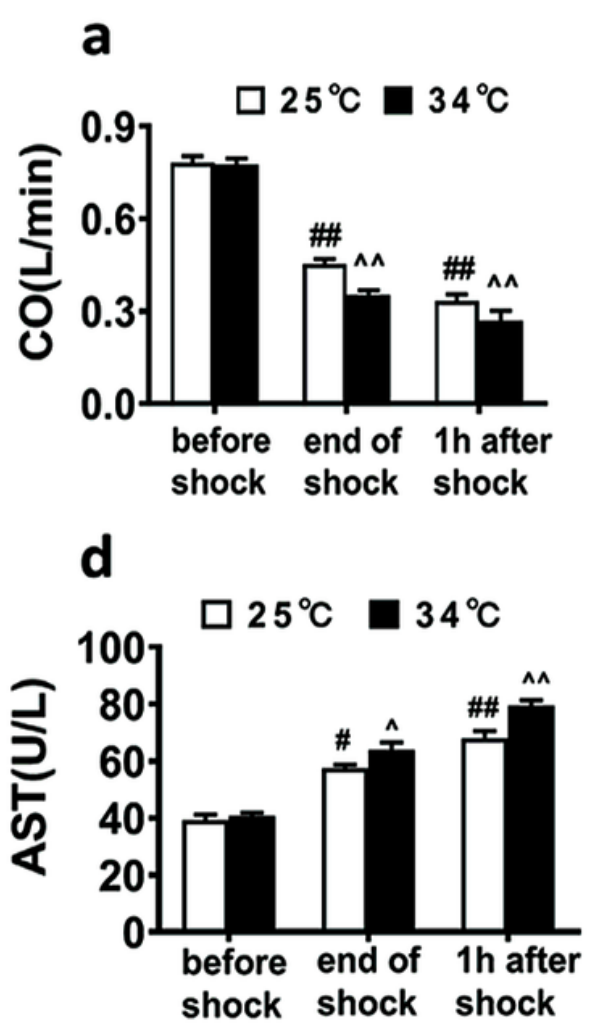

g

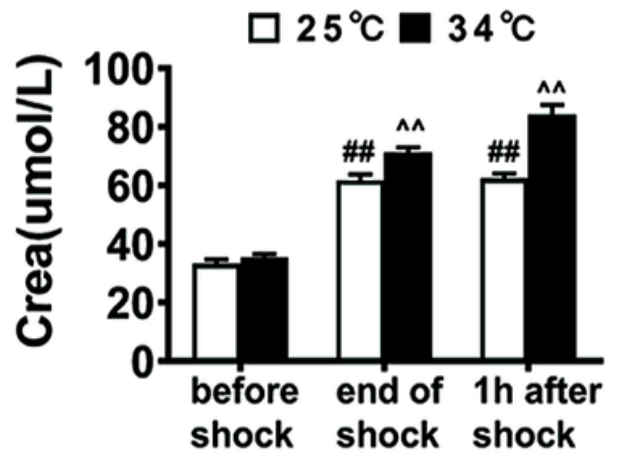

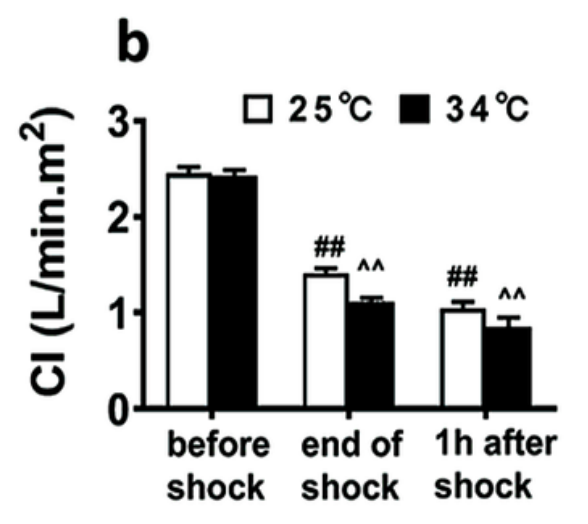
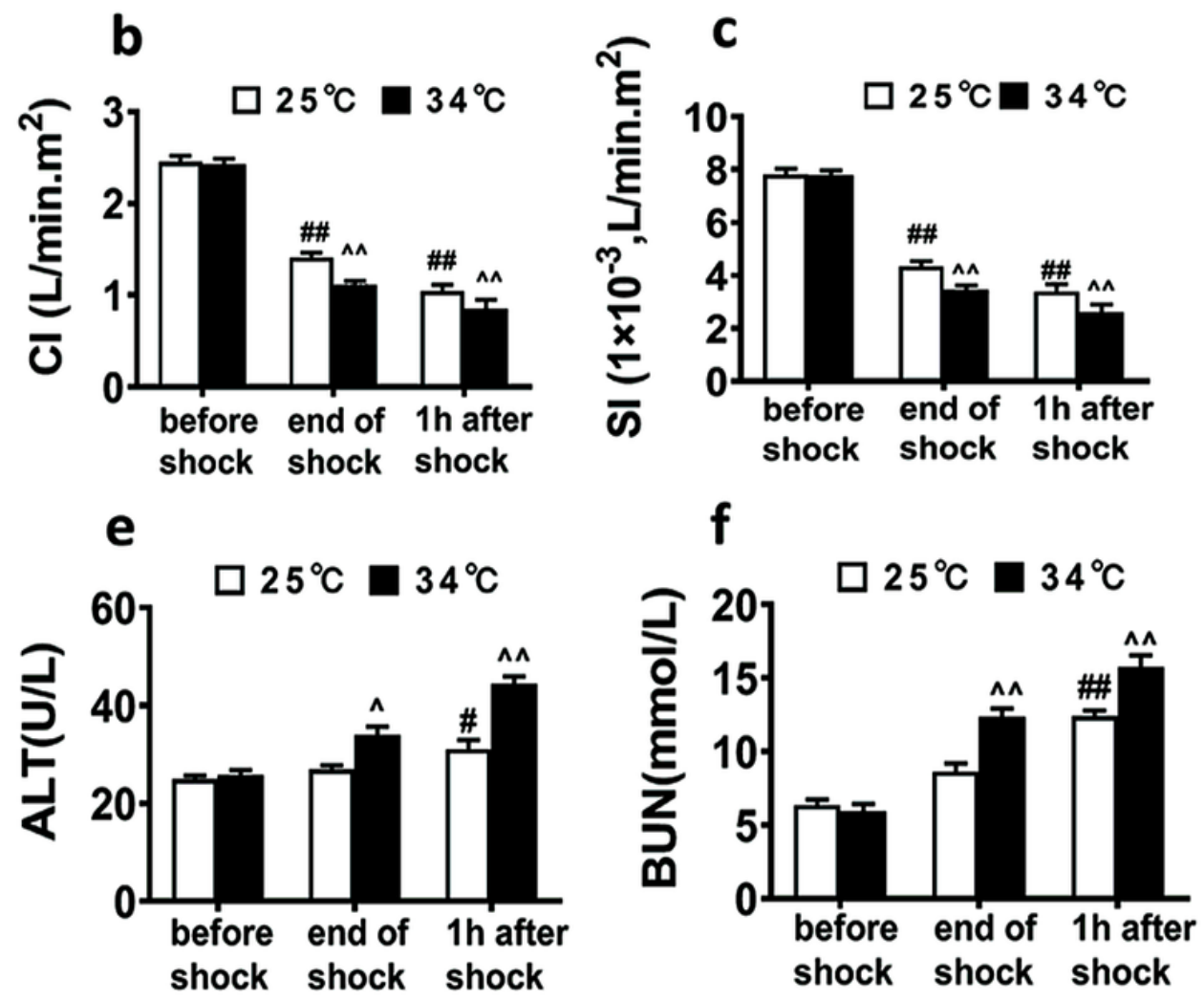

Figure 2

Changes of organ function in rats with hemorrhagic shock in hot environment. a: cardiac output (CO); b: cardiac index (Cl); c: stroke index (SI); d, aspartate transaminase (AST); e: alanine aminotransferase (ALT); f, urea nitrogen (BUN); g: creatinine (Crea). \# P『0.05, \#\#P『0.01, compared with room temperature group $\left(25^{\circ} \mathrm{C}\right)$ before shock; ${ }^{\wedge} \mathrm{P} \otimes 0.05,{ }^{\wedge} \mathrm{P} \otimes 0.01$, compared with hot environment $\left(34^{\circ} \mathrm{C}\right)$ before shock. 


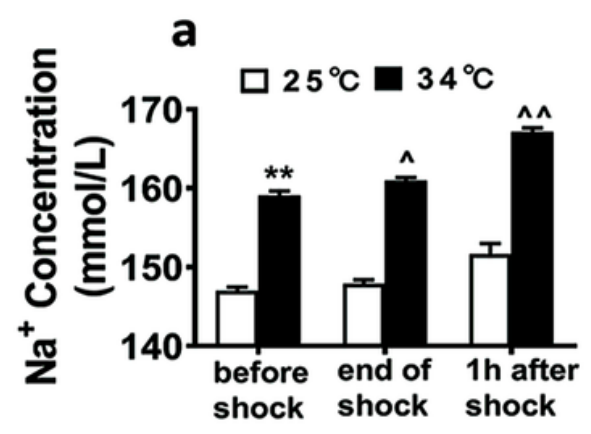

d
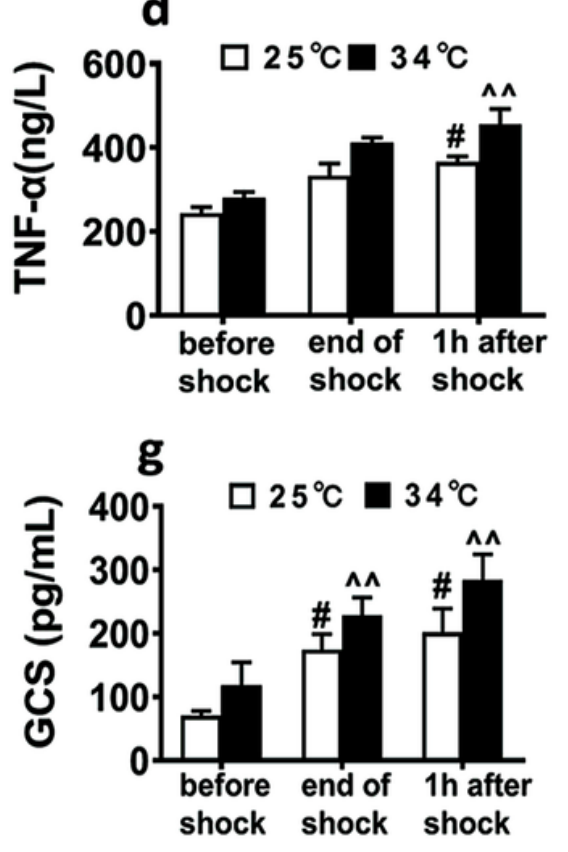

b

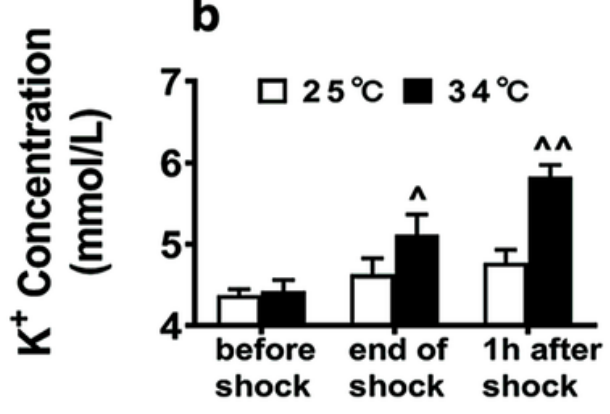

e

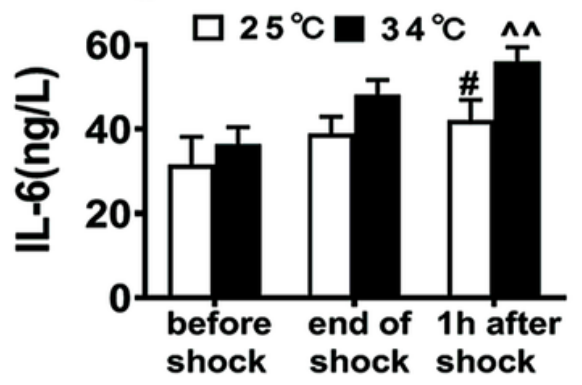

C
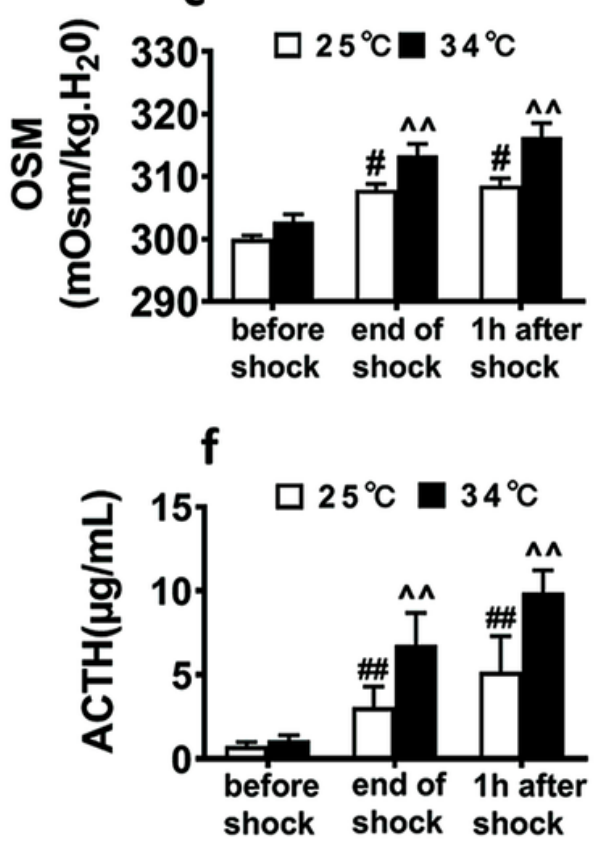

Figure 3

Changes of electrolyte, inflammatory factors and stress factors in rats with hemorrhagic shock in hot environment. a: $\mathrm{Na}+$ concentration; $\mathrm{b}$ : $\mathrm{K}+$ concentration; c: osmotic pressure (OSM); $d$ : tumor necrosis factor-a (TNF-a); e: interleukin (IL-6); f: Adrenocortical hormone (ACTH); g: Glucocorticoid *Pख0.05, **P区 0.01 , compared with room temperature group $\left(25^{\circ} \mathrm{C}\right)$; \# P凶0.05, \#\#P凶0.01, compared with room temperature group $\left(25^{\circ} \mathrm{C}\right)$ before shock; ${ }^{\wedge} \mathrm{P} \otimes 0.05,{ }^{\wedge} \mathrm{P} \otimes 0.01$, compared with hot environment $\left(34^{\circ} \mathrm{C}\right)$ before shock. 
a
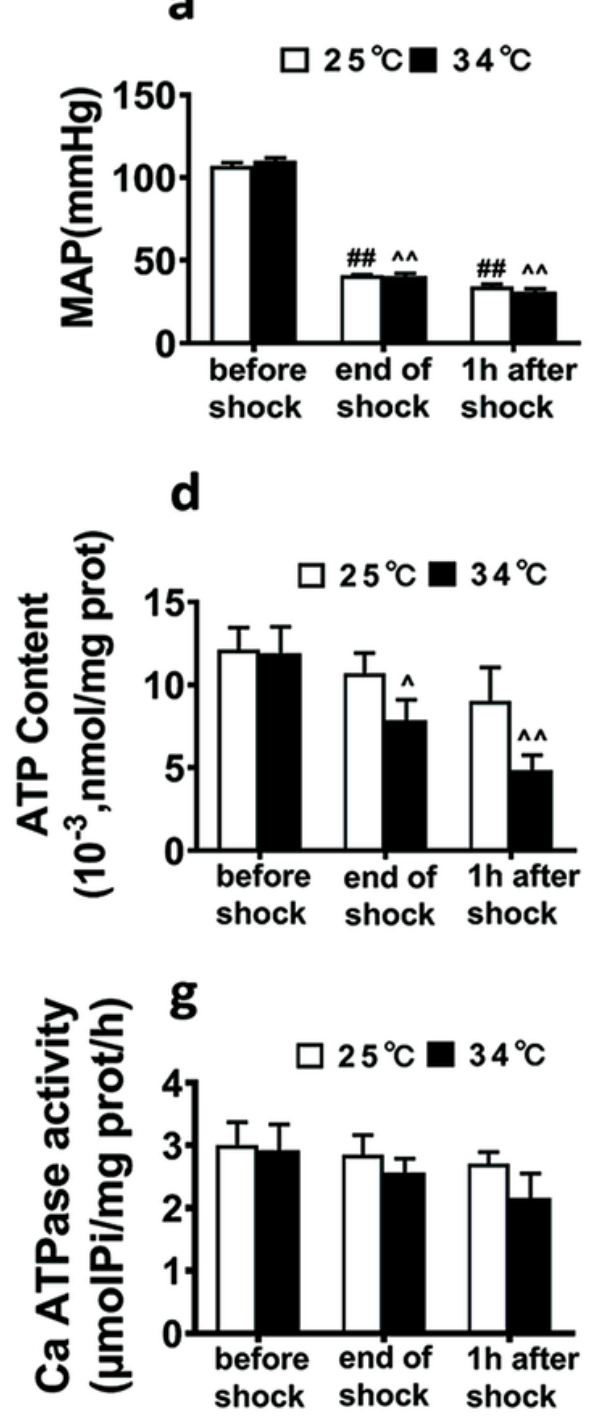

b
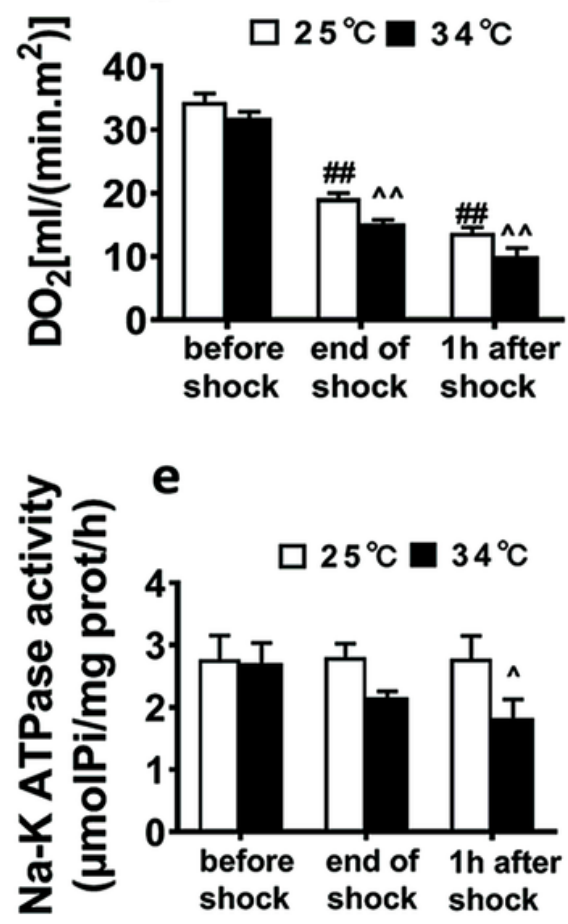

h

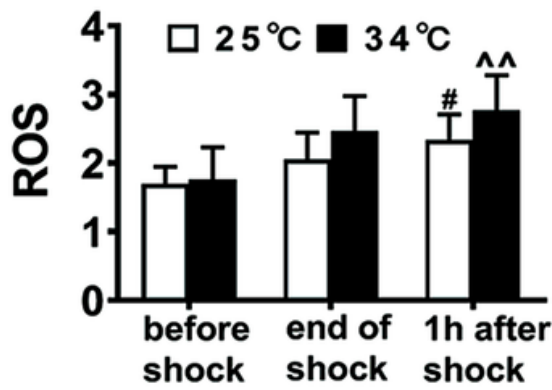

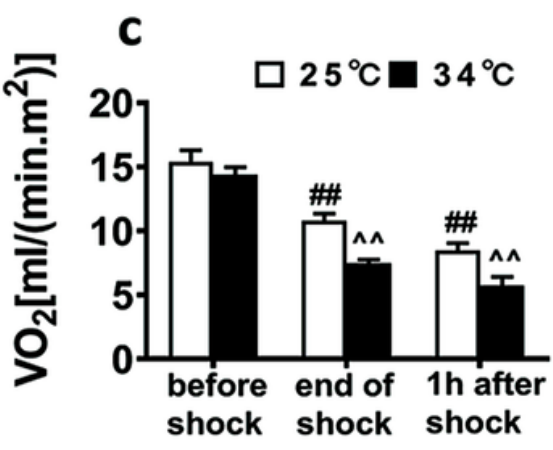

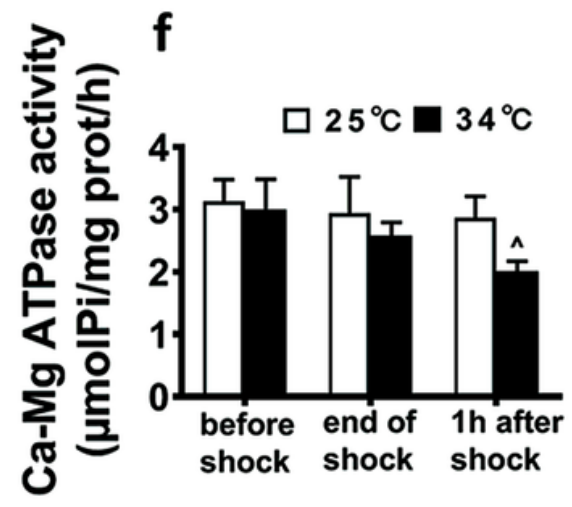

i

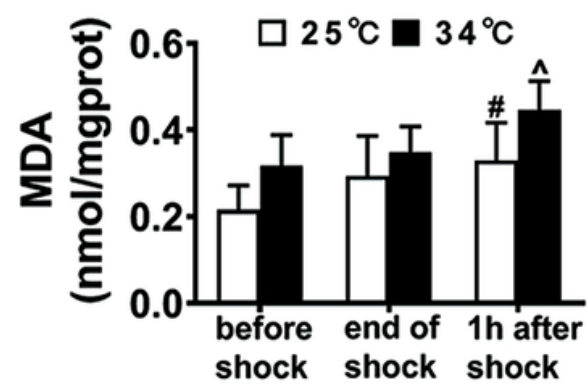

Figure 4

Changes of oxygen supply, oxygen consumption and mitochondrial function with hemorrhagic shock rats in hot environment. a: mean arterial pressure (MAP); b: oxygen delivery (D02; c: oxygen consumption (VO2); d: ATP content; e: Na-K ATPase activity; f: Ca-Mg ATPase activity; g: Ca ATPase activity; h: reactive oxygen species (ROS); i: malondialdehyde (MDA). \# P $₫ 0.05$, \#\#Pヌ0.01, compared with room temperature group $\left(25^{\circ} \mathrm{C}\right)$ before shock; ${ }^{\wedge} \mathrm{P} \otimes 0.05,{ }^{\wedge} \mathrm{P} \otimes 0.01$, compared with hot environment $\left(34^{\circ} \mathrm{C}\right)$ before shock. 

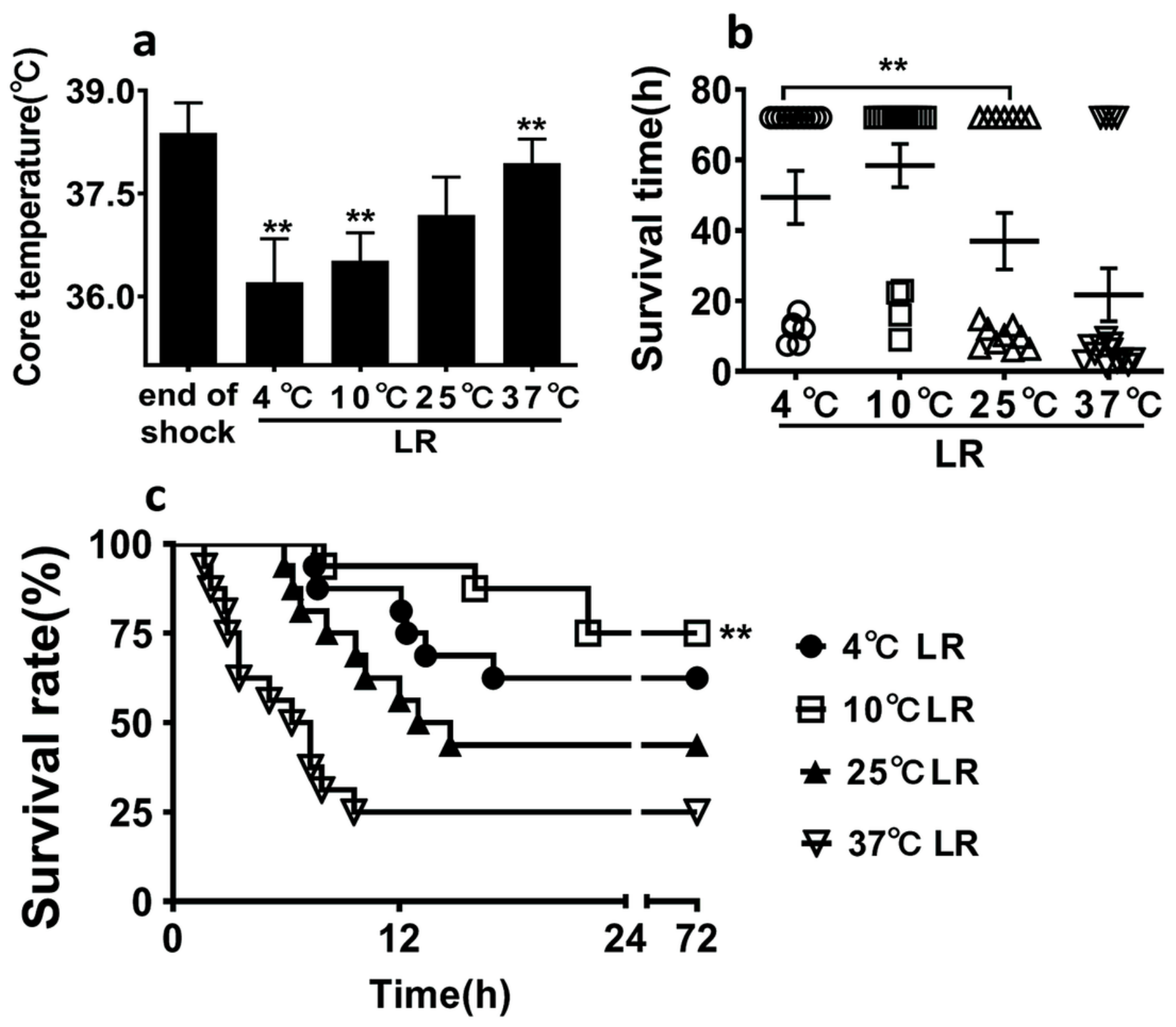

Figure 5

The effect of low temperature treatment with hemorrhagic shock rats in hot environment. a: core temperature; b: survival rate; c: survival time. ${ }^{\star \star} \mathrm{P} \otimes 0.01$, compared with room temperature group $\left(25^{\circ} \mathrm{C}\right)$.

\section{Supplementary Files}

This is a list of supplementary files associated with this preprint. Click to download.

- supplementalfig1.tif

- supplementaltable1.docx 